\title{
Proverbs as illustrative examples in a Tshivenda bilingual dictionary: A reflection of meaning and culture
}

\author{
Munzhedzi James Mafela \\ Department of African languages, University of South Africa \\ P.O. Box 392, UNISA 0003, Pretoria, South Africa \\ mafelmj@unisa.ac.za
}

\begin{abstract}
Illustrative examples are defining devices that illustrate the use of a word. They serve to illustrate the grammatical behaviour and semantic usage of the lexical item. In a bilingual dictionary, illustrative examples show the words in a live context, thereby enhancing the user's understanding of the meaning of the lexical item in the foreign language. The absence of examples usually results in a severe lowering of the standard of the dictionary (Zgusta, 1971), especially in a bilingual dictionary. A lexicographer can use either phrases or sentences, or both, to illustrate the meaning of lexical items. Van Warmelo (1989), in his bilingual dictionary, Venda Dictionary: Tshivenda - English, uses both phrases and sentences to enhance the user's understanding of the meaning of a lexical item. In addition to phrases and sentences, the lexicographer also uses proverbs and riddles as illustrative examples. This article seeks to address the question: Why does Van Warmelo use proverbs as a device to illustrate the use of a lexical item in context? The aim of the article is to exemplify the use of proverbs as illustrative examples in enhancing the user's understanding of both the meaning of lexical units and the Tshivenda culture in Van Warmelo's bilingual dictionary.
\end{abstract}

\section{Introduction}

The main function of a dictionary is to define the words of a language in terms of their characteristic features for the purpose of providing their meanings. Such characteristic features include grammatical information such as pronunciation, spelling, synonymy, parts of speech, morphology, and etymology. The inclusion of grammatical information in the definition of a word in a dictionary allows a dictionary user to understand the meaning of the headword. However, it becomes easier to grasp the meaning of a word if the word is also used in context. Using the word in context allows the user to understand its different senses, especially if the lexical item has multiple meanings. According to Kharma (1984:199), context is one of the most important characteristics that help us to understand the lexical items in sentences and passages; it is the actual situation in which an utterance occurs. The definition of a headword in a dictionary should provide both the grammatical and semantic usage of a word. As Jackson (2002:181) writes: 'All dictionaries give example sentences or phrases to illustrate meaning, grammar or usage. They are particularly numerous and prominent in learners' dictionaries, where they are seen as playing a crucial role'. Illustrative examples are valuable to a dictionary user as an aid to understanding the meaning of the headword, especially when learning another language. This brings us to the conclusion that illustrative examples are even more necessary in a bilingual dictionary than they are in a monolingual dictionary. According to Deuter (2004:245), most bilingual dictionaries are written for two language groups, each with two basic needs: encoding and decoding. In most cases, illustrative examples are given in the language that is foreign to the user. The user therefore is provided with specific information on the restrictions of word usage, thus preventing him/her from making mistakes (Fedorova, 2004:265).

All but one of the bilingual dictionaries in Tshivenda fail to provide illustrative examples in the definitions of lexical units. The one exception is the bilingual Venda Dictionary: Tshivenda-English by N.J. van Warmelo (1989). In this dictionary, the lexicographer has created his own phrases and sentences that are often accompanied by proverbs and riddles to illustrate the meaning of the headword. Through the use of the proverb, the lexicographer also reflects on the Tshivenda culture. This dictionary is meant to help non-speakers of Tshivenda to learn the language.

The article aims to exemplify the use of proverbs as illustrative examples in enhancing the understanding of the meaning of a lexical item and the culture of the Vhavenda. The Venda Dictionary: Tshivenda - English is under investigation as the only dictionary in Tshivenda that has extensively defined headwords and is mono-directional. 


\section{Illustrative examples and culture}

Al-Kasimi (1983:88) defines illustrative examples as follows: 'An illustrative example is any phrase or sentence that illustrates the use of the item defined or translated'. Illustrative examples complement the definitions of the headword. They help a dictionary user to understand the various senses of the headword by showing how the word functions in combination with other lexical units. These examples are supplied to assist the dictionary user to:

- generate sentences in the target language

- see how a word can be used in an appropriate context

- learn a foreign language with minimum difficulty.

Cowie (1989:57) indicates that illustrative examples may serve one or more of the following purposes to:

- supplement the information in a definition

- show the entry word in context

- distinguish one meaning from another

- illustrate grammatical patterns

- show other typical collocations

- indicate appropriate registers or stylistic levels.

In addition to the above-mentioned functions of illustrative examples, Al-Kasimi (1983) writes that they may be used in the dictionary to:

- prove that a word or a particular meaning of a word exists in the language

- help identify all the places where the entry word can be used.

Illustrative examples can also be used to reflect on the culture associated with a foreign language.

On the aspect of culture, Al-Kasimi (1983:92) says:

However, as far as the bilingual dictionaries are concerned, the writer suggests that illustrative examples can have an independent function. They can be selected purposefully to give the dictionary user some notions of the foreign culture he is dealing with. The culture can be illustrated to a great extent by the quotations cited in the bilingual dictionary.

This means that besides learning the meaning of the word in a definition of the headword, a dictionary user is also exposed to the culture of the foreign language through the provision of illustrative examples. Nida (1954:28) defines culture as 'learned behaviour which is socially acquired, that is, the material and nonmaterial traits which are passed on from one generation to another'. Much of the referential meaning for the receptors of any message depends upon the cultural presuppositions of a particular society (Nida \& Reyburn, 1981:14). This means that knowing the culture of a particular language plays an important role in enhancing the understanding of the meaning of a headword in a bilingual dictionary.

\section{Proverbs as a technique for reflecting meaning and culture}

Proverbs can be regarded as the experiences of a given society. Simpson, as cited by Grauberg (1989:94), says that a proverb is a 'traditional saying which offers advice or presents a moral in a short and pithy manner'. Mathumba (2000:265) defines a proverb as 'a concise, stylized metaphorical sentence, usually displaying peculiar formal features, expressing common truths, familiar to and accepted by all the members of a particular language community'.

Illustrative examples in the Venda Dictionary: Tshivenda - English are informative because they illustrate the use of the word and enhance the dictionary user's understanding of its semantic range and the culture of the Vhavenda. Al-Kasimi (1983:91) says that the function of illustrative examples in dictionaries in general and bilingual ones 
in particular, is to contribute to the user's interest by showing the word in a live context, and to enhance his understanding of the grammatical and semantic rules governing the usage of the word by showing these rules in action. The absence of examples is usually accompanied by a severe lowering of the standard of the dictionary, unless its purpose is strictly restricted to a glossary of technical terminology, for instance, or if it is purely orthographical (Zgusta, 1971).

However, Van Warmelo (1989) includes very few grammatical features in his definitions of headwords. The dictionary users are to develop an understanding of the grammatical features from the illustrative examples provided. In some definitions, the lexicographer provides the part of speech, translation equivalent and a phrase or sentence to illustrate the meaning. A proverb is sometimes also added to further enhance the user's understanding of the meaning. The definitions of other headwords are made up of translation equivalents and illustrative examples only. To illustrate this point, let us consider the definition of the verb stem -dzivhisa below:

(1) -dzivhisa forbid, prevent

Proverb: Nwana u dzivhiswa mbado, lufhanga u litsha nga ethe.

'A child is forbidden the axe; the knife it leaves alone without being told', i.e. a child should learn from experience, provided very dangerous things are kept out of its way (Van Warmelo, 1989:41).

Except for the two equivalents, no grammatical information regarding the headword -dzivhisa has been supplied, However, the dictionary user can see that -dzivhisa is a verb (stem) because of the equivalents provided, i.e. 'forbid' and 'prevent', and that the past participle (or rather passive in this case) of -dzivhisa is -dzivhiswa because of the provision of the past participles 'forbidden' and 'prevented' in the illustrative example.

A dictionary user is able to perceive all this because of the use of the word in context. The lexicographer does not make use of a phrase or a sentence as an illustrative example in this regard, but uses a proverb instead. Through the use of the proverb, the dictionary user can understand the meaning of the word (stem) -dzivhisa and its usage in context, and he/she also learns something about the Tshivenda culture. The Vhavenda do not only teach their children about matters affecting life by talking to them; they also allow them to experience life through experimentation. For example, if a child cuts himself/herself with a knife, he/she will never play with that instrument again. This means that the Vhavenda consider experience to be the best teacher; they allow their children to learn by making mistakes. When a dictionary user looks up the meaning of this word, he/she also learns about how life skills are imparted to Vhavenda children.

Similarly, in the next example of a headword, the lexicographer has a notion of the 'word' and an understanding of how it is used in context. He/she relies on a proverb to illustrate the usage of the word. The lexicographer provides the noun class and the English equivalent as follows:

(2) muputululi 1 one who unites

Proverb: Musheleli wa mushonga a si muvhulahi, muvhulahi ndi muputululi.

'The killer is not he who put in the poison, but he who untied the pouch (the supplier)' (Van Warmelo, 1989:231).

The noun class in the definition is represented by 1 in example (2) above. The proverb reflects on a truth in Tshivenda culture, namely that if something goes wrong, people are encouraged to look for the root cause. Blaming a person for committing a crime will not solve the problem; the best way to solve the problem will be to establish why the crime was committed in the first place.

Some headwords in the dictionary have more than one sense. In such cases, all the equivalents for the different senses should be provided. Kharma (1984:200) writes: 
But the most important method of providing in a dictionary the necessary 'context' for a better understanding of a word and its use is, unquestionably, to give as many examples as is practically possible for the word 'in sentences' in which the lexical item is used in various senses.

Illustrative examples are necessary when a word has different connotations or when a definition is obscure and unconvincing (Cowie, 1989). If the entry word has multiple meanings, illustrative examples must be given because they add some new information. In this regard, Van Warmelo (1989) provides not only sentences and phrases as illustrative examples, but also proverbs to further illuminate the different connotations. The example below will shed some light in this regard:

(3) -lala 1 lie down, recline. Shango lo lala - the country is at peace, quiet, without trouble. 2 lala na ndala - go to bed without supper. 3 lala musadzi or lala na - cohabit with ... 4 Vha lala vha tshi tshina - they spend the night dancing. 5 Shango li lala lo zwi divha - the whole countryside knows about it (e.g. a death) the same evening.

Proverb: Tshilavhi tshivhi ndi tsho dzhenaho itoni, tsho dzhenaho thumbuni tsho lala.

'A speck that does no good is that which gets into the eye; that which gets into the stomach will rest there'. The retort of one being reproached for eating unsavoury food (Van Warmelo, 1989:131).

Illustrative examples that define the above lexical unit are in the form of sentences, phrases and a proverb. Although the lexicographer provides sentences and phrases to explain the different senses of the headword -lala, he also provides a proverb as an illustrative example. The equivalents of -lala are 'lie down' and 'recline'. The illustrative examples bring in additional meanings, which are not included in the equivalents provided. Although the additional senses are related to the basic meaning of 'lie down', they introduce new connotations of the lexical unit -lala. In illustrative example (3) number 1 -lala means 'peace' or 'quiet', whereas in illustrative example (3), numbers 2 and 4 the lexical unit -lala is used to denote the idea of 'spending the night', i.e. spending the night without food or spending the night dancing. In number 3 of illustrative example (3) the lexicographer shows that the lexical unit -lala can be used to mean 'cohabitation' (having sex). The last illustrative example of the lexical unit -lala is a proverb. The proverb reflects both the meaning of -lala and also a further aspect of Tshivenda culture. The proverb has a message for society. The lexical unit -lala can be used to denote the idea of something trivial or harmless. The Vhavenda believe that all food, whether it tastes good or bad, does not harm a person. If a person eats unsavoury food and complains about the taste, disapproval of his/her complaint will be expressed by indicating that he/she should not worry because everything, including the unsavoury food, is accommodated in the stomach. This means that one is not expected to complain about problems one has caused for oneself. The proverb has not only been used to illustrate the meaning of the lexical unit, but also reflects on how the Vhavenda perceive an unsavoury character. According to Šarčevic (1989:211), culture-bound terms encompass a wide range of cultural patterns in a society, including its characteristic foods, clothing and sports as well as aspects of its religious, political and legal life.

In other instances, Van Warmelo (1989) uses more than one proverb to further enhance the meaning of a headword, even if it has been illustrated with phrases or sentences. He does this to reflect on the various cultural features of the Vhavenda. The definition in the example below illustrates this.

(4) -lata throw away, hence (figuratively) abandon, cast off, reject, give up (bad habits). Ndo lata! - I won't do it again. lata mutsinga - 'die'.

Proverb: A u lati ṅwana nga phadi.

'You don't disown your child because it has scabies'. A minor peccadillo or defect in another is not a reasonable cause to make a complete break with the person. 
Proverb: U lata nowa na lutanda (thanda, danda). 'Throw away the snake and the stick together'. To abjure completely, having nothing more to do with a matter (Van Warmelo, 1989:133).

All the equivalents of the headword -lata have been provided, that is, 'throw away, abandon, cast off, reject' and 'give up'. However, only two senses are illustrated with phrases, i.e. 'give up' and 'die'. Meanings such as 'throw away' and 'abandon' are not illustrated with phrases. Van Warmelo uses proverbs as illustrative examples to enhance the understanding of the senses not covered by the phrases provided. The sense of 'abandon, reject' is highlighted in the first proverb $A$ u lati inwana nga phadi. Besides the fact that the proverb reflects on the meaning of -lata, it also sheds some light on the culture of the Vhavenda. According to Tshivenda culture, if a person has a defect or has done something wrong, the family or society is not expected to reject or isolate the person. Rather, society is encouraged to stand by him/her. Hence the proverb $A$ u lati nwwana nga phadi 'You don't disown your child because it has scabies'. The second proverb is used as an illustrative example to enhance the user's understanding of one of the connotations of the headword -lata, which is 'give up (having nothing more to do with a matter)'. In this example, proverbs have been used to enhance the user's understanding of the meaning of the headword and its usage in context. In addition to this, the first proverb also reflects on the culture of the Vhavenda regarding their behaviour towards people who have defects or who have done wrong.

In other instances, Van Warmelo defines the headword by making use of explanatory phrases in English, accompanied by proverbs as illustrative examples. In the definition of the headword mutsinda, the lexicographer provides the noun class and the English equivalent followed by explanatory phrases in English. Except for the proverb, no Tshivenda phrases or sentences have been used to illustrate the meaning of the headword. The definition of the headword mutsinda is as follows:

(5) mutsinda 1 a non-relative, person not belonging to one's patrilineal kinship group, i.e. anyone who, not being descended from a common known patrilineal ancestor, may not take part in the family ancestor-cult.

Proverb: Mutsinda ndi khwine, shaka ndi bulayo.

'A stranger is better than a relative; a kinsman may be the death of one' (Van Warmelo, 1989:250).

The proverb above assists the dictionary user to fully understand the meaning of mutsinda in English, which is 'non-relative' or 'a stranger', and further enhances his/her understanding by its use in context. It also introduces another cultural aspect, which is not covered in the definition. From the definition of the headword, a dictionary user learns that each family among the Vhavenda has an ancestor-cult whose participants are descendants of a common known patrilineal ancestor. A further cultural aspect reflected by the proverb is that a stranger is trusted more than a relative among the Vhavenda. A relative cannot be trusted because of the existing conflicts in the kinship group. These conflicts may lead to hatred and some individuals wanting to eliminate others. A Muvenda would rather ask for assistance from a stranger than from a relative. This means that among the Vhavenda of the same patrilineal group, are those who often do not trust each other. They know one another's weaknesses and strengths. People are warned against trusting those who are near to them.

All the illustrative examples, including the proverbs, have been translated into the target language, which is English in this case. This enhances the user's understanding of the grammatical behaviour of the lexical unit and of how the headword functions in combination with other lexical units. However, the lexicographer does not provide an equivalent proverb from the target language; he supplies the literal translation of the proverb instead, and thereafter the interpretation of the proverb.

\section{Conclusion}

In the above exposition, it was shown that illustrative examples are important in enhancing the dictionary user's understanding of the meaning of a headword. Some lexicographers use phrases and full sentences to illustrate 
the grammatical patterning and semantic usage of the lexical units. In addition to phrases and full sentences, Van Warmelo (1989) uses proverbs, and sometimes riddles, as illustrative examples to supplement the information in the definition. Through the use of proverbs, he reflects on the culture of the Vhavenda. This information is rarely supplied by other illustrative examples. Proverbs, as illustrative examples, serve as an effective vehicle for teaching the bilingual dictionary user the meaning of lexical entries and the culture of a particular language.

\section{References}

Al-Kasimi, A.M. 1983. Linguistics and bilingual dictionaries. Leiden: E.J. Brill.

Cowie, A.P. 1989. The language of examples in English learners' dictionaries, in Lexicographers and their works, edited by G. James. Exeter: University of Exeter:55-65.

Deuter, M. 2004. A tale of two halves: Writing a bilingual dictionary for students of English, in Proceedings of the $11^{\text {th }}$ EURALEX International Congress, July 6-10, 2004, edited by G. Williams \& S. Vessier. Lorient: Universite de Bretagne-Sud:245-254.

Fedorova, I.V. 2004. Style and usage labels in learners' dictionaries: Ways of optimization, in Proceedings of the $11^{\text {th }}$ EURALEX International Congress, July 6-10, 2004, edited by G. Williams \& S. Vessier. Lorient: Universite de Bretagne-Sud:265-272.

Grauberg, W. 1989. Proverbs and idioms: Mirrors of national experience? in Lexicographers and their works, edited by G. James. Exeter: University of Exeter:94-99.

Jackson, H. 2002. Lexicography: An introduction. London: Routledge.

Kharma, N.N. 1984. Contextualization and bilingual learner's dictionary, in Lexeter '83 PROCEEDINGS: Papers from the International Conference on lexicography at Exeter, 9 - 12 September 1983, edited by R.R.K. Hartmann. Tübingen: Max Niemeyer Verlag:199-206.

Nida, E.A. 1954. Customs and cultures: Anthropology for Christian missions. New York and Evanston: Harper \& Row Publishers.

Nida, E.A. \& Reyburn, W.D. 1981. Meaning across culture. American Society of Missiology Series, No. 4. Maryknoll, New York: Orbis Books.

Mathumba, D.I. 2000. Survival of the fittest: The form of the proverb revisited, in Potent words: Studies in Southern African folklore, edited by P.M. Makgamatha. Southern African Folklore Society: Mankweng:264-272.

Šarčevic, S. 1989. Lexicography and translation across cultures, in Translation and lexicography, edited by M. Snell-Hornby \& E. Pöhl. Philadelphia: John Benjamin Publishing Company:211-233.

Van Warmelo, N.J. 1989. Venda Dictionary: Tshivenda-English. Pretoria: J.L. van Schaik.

Zgusta, L. 1971. Manual of lexicography. The Hague: Mouton. 
Copyright of South African Journal of African Languages is the property of University of Port Elizabeth, Department of African Languages and its content may not be copied or emailed to multiple sites or posted to a listserv without the copyright holder's express written permission. However, users may print, download, or email articles for individual use. 